\title{
Climate Change, Sustainable Development and Developing Countries
}

\author{
Asa Mugenyi ${ }^{1}$ \\ ${ }^{1}$ Faculty of Law, Uganda Christian University, Mukono, Kampala, Uganda \\ Correspondence: Asa Mugenyi, Faculty of Law, Uganda Christian University, Mukono. P. O. Box 5600, \\ Kampala, Uganda. E-mail: amugenyi@ucu.ac.ug; asa.mugenyi@gmail.com
}

Received: November 6, 2019 Accepted: January 4, $2020 \quad$ Online Published: March 31, 2020
doi:10.5539/ep.v9n1p45
URL: https://doi.org/10.5539/ep.v9n1p45

"The lack of action on climate change not only risks putting prosperity out of the reach of millions of people in the developing world. It threatens to roll back decades of sustainable development"

World Bank 2012. ${ }^{1}$

\begin{abstract}
This Article addresses the issue whether climate change is a myth or a reality. Can if affect development of developing countries? This article is a qualitative research on the need of developing countries to strike a balance on the options of choosing whether to pursue sustainable development goals only or addressing climate change and its effects or both. Developing countries are affected by climate change just like the developed countries. If they were to ignore it this would affect their sustainable development goals. However to address climate change, their pursuit of sustainable development is affected. Resources that would be used in achieving the goals of sustainable development are diverted to combating the effects of climate change. Developing countries lack the technology and finances to combat climate change on their own. They need developed countries to assist them. However this assistance is not forthcoming. Therefore there is a need to strike a balance between what goals to pursue. We look at Uganda as an example of a developing country that is affected by climate change and how it has coped briefly. We look at the international conventions that deal with climate change including the Paris Agreement and we see how they impact on developing countries' pursuit of sustainable development goals. Are the conventions adequate?
\end{abstract}

Keywords: climate change, developing countries, greenhouse gases and sustainable development

\section{Introduction}

Over the last few decades the international community has come to realize that the climate patterns in the world are changing. This climate change if not addressed would affect development. In order to address this The United Nations Framework Convention on Climate Change (UNFCC) was enacted which has defined climate change as a modification of the "climate attributable to human activity" where "the composition of the global atmosphere is altered over comparable time periods". ${ }^{2}$ It has three attributes: the first is variability of the climate; secondly it results from human activity which affects climate in addition to the natural climate changes; thirdly it takes place over a period of time. Though climate changes naturally with time human activity has accelerated it. Climate change involves long term shift in the weather and can be detected by changes in temperature, wind, precipitation, humidity and other indicators. ${ }^{3}$ Human activities, as noted by the Convention, such as the use of fossil fuels for energy, industrial and agricultural activities, deforestation have substantially caused an increase in emissions of green house gases (GHG) which enhance the greenhouse effect. ${ }^{4}$ GHG are defined as those gaseous constituents of the atmosphere that absorb and remit infra red radiation. ${ }^{5}$ Of the greenhouse gases,

\footnotetext{
${ }^{1}$ See also http://www.ecoostries.com Getting a global agreement on climate change retrieved January 15, 2016.

${ }^{2}$ Article 1(2) UNFCC. Climate change has also been defined as the "changing of elements of weather such as temperature, rainfall, wind over a long period of time". However the said definition does not attribute the climate change to human activities. Batte and Muhwezi (2015) Deal with climate change, boost economy.

${ }^{3}$ Afedraru (2015) Committed to reducing carbon emissions 18.

${ }^{4}$ Ibid

5 Article 1(5) UNFCC.
} 
carbon emissions have the largest effect on climate change. ${ }^{6}$ The use of fossil fuel as a source of energy is the main cause of the increase in carbon emissions. As a result of the emissions, temperature around the earth increases creating a cover of heat around the global atmosphere causing global warming. Global warming in turn affects climate patterns globally. It would be difficult to address the effects of climate change without looking at how to control carbon emissions. In order to understand the challenges met by developing countries we will take Uganda as a test case.

The UNFCC notes that there are "many uncertainties in predictions of climate change, particularly with regard to the timing, magnitude and regional patterns thereof." This means that most of the effects of climate change have not been empirically proved and are a matter of speculation. The United States (US) Congress at one time argued that there is insufficient evidence to prove the existence or effects of anthropogenic global warming, and that those carbon emissions, will hurt the US economy. ${ }^{7}$ In March 2001 the US did not ratify the Kyoto Protocol because it alleged that it was "fatally flawed and harmful to the US economy". ${ }^{8}$ However that position has since changed. The UNFCC recognises that the need to "understand and address climate change will be environmentally, socially and economically most effective if they are based on relevant scientific, technical and economic considerations and continually re-evaluated in the light of new findings in these areas." 9 The advocates states to use a precautionary approach in light of the inadequate scientific findings to "anticipate, prevent or minimise the causes of climate change".

Despite the uncertainties, climate change is deemed to have been felt in various forms, beginning with changes in the duration of seasons and their predictability, water availability or levels (at its extreme in the form of heavy rainfall resulting in floods, and droughts), extreme high and low temperatures causing fire and pest outbreaks. Climate change has been affected by man activities on the forests, mountain, aquatic and coastal ecosystems; which in turn has affected food production; human infrastructure and human health. ${ }^{10}$ Climate change affects nations economically and socially. ${ }^{11}$ Development goals of nations can be disrupted by unexpected changes in the climate.

The UNFCC notes that "the largest share of historical and current global emissions of greenhouse gases has originated in developed countries, that the per capita emission in developing countries is still low." It cannot be denied that the energy consumption levels in developing countries which are commiserate with those of their human development are low. The UNFCC recognizes that developing countries are "dependent on fossil fuel production, use and exportation, as a consequence of action taken on limiting greenhouse gas emissions." While the developed countries are the major source of green house gases, climate change also affects developing countries. ${ }^{12}$ Uganda emits 0.09 of the greenhouse emissions but the effects on her are not proportional to her contribution. ${ }^{13}$ Developing countries are severely affected more by changes in the climate than developed countries. ${ }^{14}$ In order to address this and the causation of climate change the Convention promotes an equitable provision of shouldering the burden between the developed and developing countries. ${ }^{15}$ The Convention requires developed countries to take the lion share of responsibility in addressing climate change. Developed countries which have been using fossil fuels since the time of the industrial revolution, now use renewable energy. Most developing counties never got the chance to use fossil energy to attain the level of development of the developed countries. They cannot afford to use renewable energy to the level of developed countries. However we also have to take into consideration that China and India though developing countries are among the largest carbon dioxide emitters. ${ }^{16}$ They are likewise affected. Though there is a lot of agitation by developing

\footnotetext{
${ }^{6}$ Intergovernmental Panel on Climate Change Stabilisation of atmospheric greenhouse gases: Physical, biological and socio-economic implications. 3 IPCC Technical Paper III. Green House Gases include Methane (CH4), Nitrous Oxide NO3 from fertilisers, Hydro fluorocarbons (HFCS), Per fluorocarbons ((PFCS), Sulphur Nexa Fluoride (SF6) from dielectric fluids See .Annex A Kyoto Protocol

${ }^{7}$ Kiss and Shelton (2002) International Environment Law 326.

${ }^{8}$ Ibid.

${ }^{9}$ Preamble UNFCC

${ }^{10} \mathrm{Op}$ cit No.7 4

${ }^{11}$ Mugabe (2015) Let us fight climate change - PM 26.

${ }_{12}$ Annex I to the UNFCCC considers members of the OECD as developed countries. Emissions from fossil fuel energy contribute to over $80 \%$ of total $\mathrm{CO}_{2}$ emissions in 2000 while land-use changes contribute negligible amounts of emissions (Table 12.1). Jaynant Sathaye and Ail Najam Sustainable development and mitigation. 704

${ }^{13}$ Kagumire (2015) Kaumuntu pushes for fair climate accord 8

${ }^{14}$ Sathaye and Najam (2002) Sustainable development and mitigation 704

${ }^{15}$ Ibid.

${ }^{16}$ Le Bourget (2015) Joy, relief as climate deal is adopted. www.Learnmoreeconomist.com/story retrieved on January 42016.
} 
countries for the developed countries to shoulder the burden of addressing climate change, the big developing country polluters are ignored. When dealing with such developing countries they should be considered in a different category, of developed countries. In their pursuit for sustainable development the emissions from developing countries is bound to increase.

Developing countries like Uganda are not spared. In Uganda, climate change has been felt in the form of uncertain and unpredictable weather patterns that have affected the economy. It has caused "long and heavy droughts, uncertain weather patterns where the previously known rain seasons of early and mid-year have shifted and are no longer predictable..."17 The frequency and timing of rainfall has changed. In certain situations intensive rainfall has resulted in floods while prolonged absence of rainfall has resulted in droughts and famine. In Uganda, there have been landslides in Bududa, floods in Rwenzori and Teso. ${ }^{18}$ However the said calamities cannot be wholly attributed to climate change. This is because the human degradation and improper use of the said environment can cause the same effects. Some of the calamites attributed to climate change are actually a result of improper use of the environment by man. Change of seasons can affect crop yields. It is noted that climate change is "hurting food production and risking man's survival". ${ }^{19}$ A drought in 2009 caused a loss of US $\$ 1.3$ billion in GDP because of crop failure ${ }^{20}$ Estimate from the World Bank indicate that the 2010/1 drought alone cost Uganda about 7\% of its GDP (Shs. 5.6 trillion). ${ }^{21}$ The agricultural sector has declined due to climate change. Climate change has also affected electricity generation. In 2010, water levels in Lake Victoria dropped. As a result there was less electricity generation resulting in more load shedding. The Minister of Water and Environment of Uganda in respect of the country stated that "If we continue to suffer climate change effects like this then our chances of development are limited". 22

\section{Tackling Climate Change}

Tackling climate change involves either mitigation or adaptation. Mitigation involves addressing the climate change using a preventative approach in limiting GHG. There are many ways countries may reduce GHG emissions such as such as improving energy efficiency as well as change from the outdated sources of energy, afforestation, reducing deforestation, air pollution control, and restructuring transportation. Some of the mitigation options may improve productivity and promote sustainable development and others may have important impacts on national economies such as job creation, soil and water conservation. While countries are required to mitigate, measuring how mitigation can be achieved is not clear. For instance, if a country promises to reduce her emissions by $20 \%$ how is this measured? Secondly, in order to reduce GHG there is need to eliminate the use of sources of carbon emissions; coal, oil and gas for energy, which have propelled nations into prosperity. It would be difficult for developing countries to achieve their sustainable development goals if it involves reducing the emissions of the above sources of energy. The developing countries lack the technology and the funding for cleaner sources of energy such as wind, solar and nuclear.

Adaptation involves communities acclimatizing to the vagaries of climate change so that there is no fundamental interference with their activities. Under adaptation the impacts resulting from the increased concentrations of greenhouse gases are addressed in a reactive way to suit human activity. Adaptation has been promoted as the best means of obtaining development in light of climate change. ${ }^{23}$ The adaptation approach is more relevant to developing countries which are striving to meet the challenges of climate variability and do not have the technology and finances to prevent it. The technology used by most developing countries is not useful in reducing emissions. As climate change challenges goals of sustainable development, the governments need to invest in climate change adaptation. There should be climate adaptation interventions to reduce climate vulnerability keeping development in mind. However adaptation measures should be a complimentary response strategy to mitigation. Having adapted to climate change there is a need to mitigate its effects. Mitigation may involve wider use of solar energy, afforestation, control of carbon emissions etc. This can be achieved after

\footnotetext{
17 Op cit no. 12.26

18 Batte and Muhwezi (2015) Deal with climate change, boost economy 6.

19 Op cit no. 12

20 Ibid.

21 Ibid.

22 At the $21^{\text {st }}$ Conference of the Parties to the United Nations Framework Convention on Climate Change. Kamuntu pushes for fair climate accord 8 .

23 Brooks "Using Wellbeing indicators and information to assess adaptation effectiveness." Briefing December 2001. The author argues that "The ultimate purpose of adaptation is to secure and improve human wellbeing — in line with national development priorities — in the face of climate change."
} 
sustainable development bringing in the required technology and finance. Most developing countries prefer to adapt to climate change than mitigation as they are vulnerable to climate change and do not have the resources and technology to mitigate.

Uganda plans to reduce carbon emissions by $22 \%$ by $2030 .{ }^{24}$ The Ministry of Water and Environment is seeking to combat climate change under the Uganda National Climate Change Policy and the Uganda Green Growth Strategy supported by the United Nations Development Programme (UNDP) and involves measures such as use of renewable energy such as solar energy, afforestation etc. ${ }^{25}$ The need to address climate change has been addressed by Vision 2040. The National Development plans have emphasised the need to address climate change. To adapt to climate change the government has put initiatives like rainwater harvesting, irrigation etc, As regards mitigation the government aims at investing in renewable energy projects under the Climate Investment Funds (CIF). The funding will help on geothermal exploration, development of wind energy and building mini grids. However financial planning by developing countries to combat climate change is made difficult due by the unavailability of studies to show how climate change has impacted on their economies.

\section{Climate Change, Sustainable Development and Developing Countries}

Sustainable Development has been defined by the World Commission on Environment and Economy as "development that meets the needs of the present without compromising the ability of future generations to meet their own needs. ${ }^{26}$ Sustainable development is one of the millennium goals. Though widely cited, there is no agreed fixed position on how it should be applied. It can be traced to the notion of a sustainable society capable of managing its resources such that the livelihood of future generations is not threatened. ${ }^{27}$ One of the principles also adopted at the World Commission is that states shall "maintain ecosystems and related ecological processes essential for the functioning of the biosphere in all its diversity, in particular those important for food production, health and other aspects of human survival and sustainable development." Climate change hinders sustainable development by diverting resources that would be allocated for development to mitigate it or combat its effects. To avoid this States should endeavor to maintain the world climate patterns so that the present and future generations are not affected.

The UNFCC promotes the concept of sustainable development. Under Article 3 of the UNFCC the parties should protect the climate system for the benefit of the present and future humankind. Under Article 3(4) of the UNFCC the parties have a right and should promote sustainable development. Despite the affirmation of the principle of sustainable development the UNFCC does not elaborate modalities on how it can be achieved in respect of the climate.

One cannot divorce economic development from environment management. Sustainable development requires integrating economic, social processes with those of the environment. Principal 4 of the Rio Declaration states that "in order to achieve sustainable development, environmental protection shall constitute an integral part of the development process and cannot be considered in isolation of it." Since the 1992 Earth Summit in Rio de Janeiro, there is consensus that sustainable development involves integrating economic, social and environment processes. The UNFCC affirms that the "responses to climate change should be coordinated with social and economic development in an integrated manner with a view to avoiding adverse impacts on the latter, taking into full account the legitimate priority needs of developing countries for the achievement of sustained economic growth and the eradication of poverty."

There is a challenge in implementing sustainable development in collaboration with environment management in addressing the effects climate change has on developing countries. A developing country has to choose between sustainable development, protecting the environment in order to prevent and mitigate climate change or both. If Uganda does not address the issue of climate change it stands to lose about US\$ 270 billion, which is about 10 times her current total earnings, in the next 50 years. ${ }^{28}$ There will be less water for electricity generation, consumption and industrialisation. Uganda will need about US\$ 406 billion in the next five years to mitigate climate change impacts. ${ }^{29}$ This would be at the expense of other sustainable development goals. There are two questions that arise in respect of climate change, sustainable development and developing countries.

\footnotetext{
${ }^{24}$ Op cit no. 4.

${ }^{25}$ Ibid.

${ }^{26}$ WCED, 1987

${ }^{27}$ Op cit no 15. 5.

${ }^{28}$ Nantambi (2015) Climate Change: Uganda to lose Sh. 945 trillion.

${ }^{29}$ Tajuba (2015) How Climate Change is set to affect key economy sectors 34.
} 
The first question is on priority of needs: whether developing countries should address the issue of climate change before that of development or vice versa. Developing countries are affected by drought, famine, floods etc resulting from climate change. Climate change is caused by the rampant use of fossil energy. In developing countries the levels of energy production and consumption are low and infrastructure is poor. ${ }^{30}$ Sathaye and Najam note that:

"Less industrialized countries often have poor infrastructures, exacerbated by lack of human, financial, and technological resources. In addition, these countries are likely to focus on more basic considerations of nation building and economic development. The economic conditions of less-industrialized countries also present opportunities to achieve both sustainable development goals and emissions reductions measures at lower cost than in the industrialized countries. ${ }^{31}$,

If they are to focus on climate change first they may not achieve sustainable development. In order to achieve sustainable development there is need to increase the production and consumption of energy which affects the emission of GHG and in return increase global warming. For developing countries to develop economically carbon emissions will first rise and with time they begin to decline. ${ }^{32}$ Improved use of fossil energy for developing countries means increasing GHG emissions. ${ }^{33}$ The UNFCC realizes that the "energy consumption of developing countries will need to grow taking into account the possibilities for achieving greater energy efficiency and for controlling greenhouse gas emissions in general". At the G8 summit at Gleneagles in 2005 it was acknowledged that the world energy demand is expected to increase by $60 \%$ in the next 25 years as energy supplies are necessary for economic development. Hence there is need for developed countries to work with developing countries to access low emitting energy systems. ${ }^{34}$ The developing countries have to weigh development benefits against climate benefits and choose which development sectors need streamlining. There may be a need to make tradeoffs between development processes and environmental concerns. Development may be made more sustainable by changing development paths to accommodate climate goals. ${ }^{35}$

The second question is how development countries can achieve sustainable development without causing further climate change. However it has been argued that economic development comes with improved technological changes that may be able to combat climate change. Sathaye and Najam argue that:

"Economic activity is a key driver of $\mathrm{CO}_{2}$ emissions. How economic growth translates into new emissions, however, is ambiguous. On one hand, as the economy expands, demand for and supply of energy and of energy-intensive goods also increases, pushing up $\mathrm{CO}_{2}$ emissions. On the other hand, economic growth may drive technological change, increase efficiency and foster the development of institutions and preferences more conducive to environmental protection and emissions mitigation. ${ }^{36 "}$

Therefore it is argued that economic development may not affect climate change. It is our argument that there is still need for developing countries to adopt appropriate mitigation measures and technology consistent with its sustainable development priorities

Developing countries can make development more sustainable by tuning their development plans in such a way that climate goals are incorporated and made more significant. Developing countries should link sustainable development with plans to combat climate change because of their limited resources and other priorities. ${ }^{37}$ Developing countries have to determine the relationship between sustainable development and climate change because of their level of development and the climate challenges they may face. ${ }^{38}$

\footnotetext{
${ }^{30}$ Ibid 706. "Nearly half the world's population depend on solid fuels, including wood, dung, crop residues and coal, to meet their most basic energy needs. In developing countries, forests contribute to the emission and absorption of green house gases. Cutting trees for charcoal and firewood affect the emission of $\mathrm{CO} 2$ while deforestation affects the absorption." Source: Progress towards the Millennium Development Goals, 1990-2005 http://unstats.un.org/unsd/mi/mi_coverfinal.htm

${ }^{31}$ Ibid. 709.

32 Energy and Resource Institute Climate Change, Mitigation and Sustainable development 4.

${ }^{33}$ Op cit no. 15707.

${ }^{34}$ Op cit no 3117.

${ }^{35}$ Op cit no. 15. 704 .

${ }^{36}$ Ibid no. 15707.

${ }^{37}$ Op cit no. 3216

${ }^{38}$ Op cit no. 155
} 


\section{The International Legal Framework on Climate Change viz a viz Developing Countries}

\subsection{United Nations Convention on Climate Change (UNFCCC)}

The main objective of the UNFCC is to prevent the dangerous anthropogenic effects of GHG emitted by nations interfering with the climate system. ${ }^{39}$ Nations need to stabilize the concentrations of GHG to suitable levels so as not to threaten food production and sustainable development. ${ }^{40}$ How to make the objective of the UNFCC operational has been a subject of various interpretations. ${ }^{41}$ The UNFCC does not provide a time-frame for nations to stabilize GHG concentrations so as to allow ecosystems to adapt naturally to climate change. Neither does the Convention set specific stabilization levels, pathways nor targets when emissions would be reduced to stable levels. ${ }^{42}$ The omission to set targets for reduction to acceptable levels makes it difficult to discern whether the UNFCC is achieving its goals.

In Annex I to the UNFCC Convention there are thirty six countries plus the European Community which are considered as developed countries. Those countries that are not listed in the annex are considered as developing countries. Compared to developed countries which have greater finances and technology developing countries have historically contributed less to the emission of GHG. ${ }^{43}$ Developing countries argue that they cannot solely address the problem of climate change as they did not create it. ${ }^{44}$ The developing counties cannot forego their development programs to invest in mitigation and adaption of climate change unless supported by the developed countries. ${ }^{45}$ The UNFCC imposes a bigger burden on the developed countries in addressing the issue of climate change. It advances the principles of "common but differentiated responsibilities" and that of "respective capabilities" which urge developed countries to take the lead in the tussle of climate change. ${ }^{46}$ However carbon dioxide emissions in developing countries have increased while in developed countries have remained stable. This can be a source of further discontentment. For instance, in the Fourth Conference of Parties to the UNFCC held in Buenos Aires from November 2 to 14 1998, the developing countries did not accept any obligation to have their GHG emissions reduced. ${ }^{47}$ The US Congress opposed the absence of commitments by developing countries. ${ }^{48}$ It raises issues of equitable reduction of GHG emissions and the need to address past mistakes. Should the convention be more concerned addressing the effects of past emissions or dealing with future emissions? Developing countries are reluctant to reduce their emissions as they have not reached the level of development of the industrialized countries. To attain that level of economic development they may have to inadvertently increase their levels of GHG emissions. In achieving the said development they would have aggravated climate change. So there is need to balance development with protection of the climate.

The UNFCC emphasizes that "all countries, especially developing countries, need access to resources required to achieve sustainable social and economic development." Under Articles 4(3)(4) and (5) of the UNFCC the developed countries shall provide financial assistance to developing countries to meet their obligations under the Convention especially for those "that are particularly vulnerable to the adverse effects of climate change in meeting costs of adaptation to those adverse effects". The most developed countries must "assist developing countries that are particularly vulnerable too adverse effects of climate change in meeting costs of adaption to those adverse effects". ${ }^{49}$ Under the UNFCC Article 4(9) "the Parties shall take full account of the specific needs and special situations of the least developed countries in their actions with regard to funding and transfer of technology." The UNFCC parties established three funds; two under the UNFCC and one under the Kyoto Protocol to assist developing countries comply with the requirements. Decision 7/CP.7 created "a special climate change fund" to provide for finances for the adaptation, technology transfer, and the mitigation of green house gases. The second fund is reserved for the least developing countries to assist financially in the preparation of national programs. ${ }^{50}$ This helps developing meet the finances of combating and mitigating the effects of climate

\footnotetext{
39 Article 2 UNFCC.

${ }^{40}$ Ibid

${ }^{41}$ Op cit no. 33.7 .

42 Op cit no. 717.

${ }^{43}$ Op cit no. 33.7.

${ }^{44}$ Musasizi (2015) Pay climate change cash, rich nations tell Africa. 9.

${ }^{45}$ Ibid.

${ }^{46}$ Article 3(1) UNFCC.

${ }^{47}$ Op cit no. 8324.

${ }^{48}$ Op cit no. 8326.

${ }^{49}$ Article 4(3)(4) UNFCC

${ }^{50}$ Op cit no. 8169 .
} 
change. It also allows them allocated funds to pursue sustainable development. However developing countries do not have sufficient funds to combat climate change and its effects. The UNFCC does not set targets of funds that would be raised to help in developing countries in fighting climate change. The adaption funds depend on voluntary contributions by developed countries.

One of the bottlenecks to combating climate change is the lack of appropriate technology by developing countries. Some developing countries like China are heavily dependent on coal for its energy requirements while those in Africa like Uganda still use firewood for their domestic energy demands. It is not doubted that developing countries mostly use technology that relies on fossil energy which emits a lot of GHG. These countries need technical cooperation to combat climate change and achieve sustainable development. ${ }^{51}$ In this regard, the UNFCC requires developed country parties to "promote, facilitate and finance, as appropriate the transfer of, or access to environmentally sound technology and know-how to developing countries." ${ }^{, 52}$ Under Article 4(3) of the UNFCC the developed countries shall also provide the transfer of technology needed by developing country Parties to meet the agreed some of their commitments. In order to achieve the transfer of technology in combating climate change the UNFCCC process established an Expert Group on Technology Transfer. The work of this Expert Group is to analyze and identify ways of advancing technology transfer under the UNFCCC. ${ }^{53}$ The UNFCCC also provided for means of financial support for the technology transfer through the establishment of a Global Environmental Facility (GEF) which gives grants/ loans to those projects which meet the criteria under the convention. ${ }^{54}$ Despite the above mechanisms it is argued that the transfer of technology has remained unfulfilled. Most governments have commercialised the transfer of technology which is patented. ${ }^{55}$ Nevertheless developing countries have integrated climate friendly measures into their sustainable development programs. ${ }^{56}$ Though there is progress in developing efficient energy and there is better access to clean technology the transfer of new technologies to the developing countries is not corresponding to their energy demands. ${ }^{57}$ There cannot sustain development without appropriate technology.

\subsection{The Kyoto Protocol}

The Kyoto Protocol, made under the UNFCC, is also concerned with monitoring of GHG. It sets further reduction obligations for developed countries concerning future emissions of GHG without corresponding commitments for developing countries. The Protocol requires developing countries to establish national systems to estimate GHG emissions by the various sources and the removal of the said emissions by sinks. ${ }^{58}$ Article 10 and 11 of the Protocol do not limit the emissions of developing countries but require them to formulate and use relevant, appropriate cost effective national regional programs to mitigate climate change as well as publishing and regularly updating the said programs taking into account all relevant economic activities. The developing countries are also required to keep annual inventories containing information necessary to demonstrate compliance with the commitments accepted under the Protocol. ${ }^{59}$ Such information is reviewed by teams composed of experts nominated by parties to the UNFCC.

The Protocol further established a Clean Development Mechanism (CDM) to assist developed countries reduce GHG emissions and developing countries achieve sustainable development. ${ }^{60}$ The bulk of the projects under the $\mathrm{CDM}$ involve those that mitigate carbon emissions by providing non- $\mathrm{CO}_{2}$ gases. ${ }^{61}$ The state Parties in the CDM projects obtain certified emission reductions (CER) credit by reducing carbon emissions. The CDM channels huge amounts of money to developing countries to purchase carbon credits. ${ }^{62}$ Developing countries are able to

\footnotetext{
${ }^{51}$ Op cit no.32 18.

52 Article 4(5) UNFCC.

${ }^{53}$ Op cit no. 3113.

${ }^{54}$ Article 11 UNFCC.

${ }^{55}$ Op cit no. 3115.

${ }^{56}$ Ibid 18.

${ }^{57}$ Ibid 17.

58 Article 5 UNFCC.

${ }^{59}$ Article 7 UNFCC.

${ }^{60}$ Article 12 UNFCC.

${ }^{61}$ Article 12(3) (b) UNFCC.

${ }^{62}$ Op cit no. 13 733. In 2005, the CDM channelled about US $\$ 2.5$ billion to purchase carbon credits in developing countries or $0.75 \%$ of the (record) net foreign direct investment (FDI) inflow in developing countries for that year (UNCTAD, 2006). In addition, it can be argued that the CDM leverages new private capital to developing countries and very little financial flows towards least developed countries, notably in Sub-Saharan Africa (Capoor and Ambrosi 2006)
} 
achieve sustainable development under CDM project activities through getting climate friendly technologies, investments, increased employment and economic activity. ${ }^{63}$ The Protocol enhances cooperation between developed countries and developing countries by promoting the transfer of "environmentally sound technologies, know, practices and processes pertinent to climate change as well as capacity building". Article 11 provides for new and additional financial resources to meet agreed full costs incurred by developing country parties in advancing the implementation of existing commitments.

The UNFCC and the Kyoto Protocol specifically encourage afforestration and reforestation and permit state party to meet their obligations under the Protocol in part by such actions. ${ }^{64}$ Reducing deforestation may reduce GHG emissions but may result in loss of economic welfare for some stakeholders. It is still a challenge for developing countries to balance the need to reduce global carbon emissions so as to attain climate change goals with the need to achieve development. ${ }^{65}$ However, in some cases, it may be rational to disregard climate change considerations because of the small increase in emissions compared with its development benefits.

\subsection{The Paris Agreement (2015)}

It was under the framework of the UNFCC that the Paris Agreement of 2015 was made to regulate $\mathrm{CO}_{2}$ reductions from 2012. The agreement facilitates the ability of countries to adapt to the adverse effects of climate change. Under the said Agreement all the countries party to it are required to limit their emissions to a safe level of $2^{0} \mathrm{C}$ above pre-industrial levels with an aspiring intention of obtaining a level of $1.5^{\circ} \mathrm{C}$. Nations are encouraged to communicate their agreed reductions of GHG emissions. Article 9 of the Agreement requires developed countries to assist financially developing countries parties to the agreement with respect to mitigation and adaptation. It is feared that the need to communicate their nationally determined contributions may be a trap to developing countries that may seek financial assistance. If the developed countries are not satisfied with their reduction goals the developing countries may not get the assistance. The agreement has its limitations. Though the Agreement was approved by consensus it still requires 55 countries to ratify before it comes into force. It does not set targets. Countries are required to set down their ambitions and plans for reduction in emissions. However it does not say about how much any country is required to do. The agreement does not provide for penalties for those countries which fail to comply with their reduction emissions. Though it requires developed countries to assist financially developing countries, there are no monetary commitments. Not all the agreement is legally binding. There is no action plan for the pre- 2020 period yet carbon emissions are still taking place.

Despite the making of the UNFCC the Kyoto Protocol and the Paris Agreement the emissions from industrialized countries and of developing countries, continued to rise. ${ }^{66}$ It appears the commitments in the UNFCC and the Protocol are not effective to achieve their intended goals. The Protocol is complex which increases the risk of disagreement over the interpretation of its text and implementation. ${ }^{67}$ The recent Paris Agreement in December 2015 required countries to take bolder steps in combating climate change. However it does not provide for concrete steps that would substantially reduce carbon emissions.

\section{Conclusion}

In order to achieve sustainable development, there is need to integrate environmental and climate change concerns into the programs of developing countries. Sustainable development cannot be achieved at the expense of the environment and the climate. To shut out the need to protect the environment and the climate would adversely affect development in the long run. Developing countries need to prioritize mitigation of climate change over adaptation to climate change. There is need to put stringent terms under the Paris Agreement setting out clear commitments for developing countries among others to reduce their GHG emissions.

The issue of transfer of technology and finance from developed countries should be addressed effectively in the UNFCC and its protocol. Developed countries should assist developing countries benefit from appropriate technology to enable them reduce climate change and address its effect at same time allowing them to pursue their goals of sustainable development. There should be a pool set up under the agreement that enables financing of appropriate technology transfer from developed to developing countries. However developing countries should not rely solely on developed countries to fund their efforts to combat climate change. The developing countries can contribute to a common fund that can be used.

\footnotetext{
${ }^{63}$ ccu.go.ug/index.php

${ }^{64}$ Article 3(3) UNFCC.

${ }^{65}$ Op cit no. 15. 733 .

${ }^{66}$ Op cit no. 8322.

${ }^{67}$ Ibid.
} 


\section{References}

Afedraru, L. (2015, November 12). Committed to reducing carbon emissions. Daily Monitor.

Batte, E. R., \& Muhwezi, O. (2015, August 19). Deal with climate change, boost economy. Daily Monitor 6.

Brooks, N. (2015 December). Using Wellbeing indicators and information to assess adaptation effectiveness. Briefing.

Energy and Resource Institute. Climate Change, Mitigation and Sustainable development.

Getting a global agreement on climate change. Retrieved from http://www.ecoostries.com

Intergovernmental Panel on Climate Change on Stabilisation of atmospheric greenhouse gases: Physical, biological and socio-economic implications 3 IPCC Technical Paper III.

Kagumire, R. (2015, December 6). Kamuntu pushes for fair climate accord. Daily Monitor. 8.

Kiss, A., \& Shelton, D. (2002). International Environment Law. United Nations Environment Programme.

Le Bourget. (2015, December 14). Joy, relief as climate deal is adopted. New Visions (AFP).

Mugabe, D. (2015, July 6). Let us fight climate change - PM New Vision 26 reporting on Ruhakana Rugunda during a climate change discussion organized by the World Bank at Kampala Serena Hotel.

Musasizi, S. (2105, November 11). Pay climate change cash, rich nations tell Africa. New Vision 9.

Nantambi, A. (2015, December 14). Climate Change: Uganda to lose Sh945 trillion. New Vision 42.

Sathaye, J., \& Najam, A. (2002). Sustainable development and mitigation.

Tajuba, P. (2015, December 14). How Climate Change is set to affect key economy sectors. Daily Monitor.

The United Nations Framework Convention on Climate Change.

\section{Copyrights}

Copyright for this article is retained by the author(s), with first publication rights granted to the journal.

This is an open-access article distributed under the terms and conditions of the Creative Commons Attribution license (http://creativecommons.org/licenses/by/4.0/). 